\title{
IMPACT OF INTRATHECAL CLONIDINE ON LABOUR PROGRESSION AND MATERNAL FOETAL WELLBEING: OUR EXPERIENCE
}

\author{
Marco Aversano', Claudia Claroni', Gabriella Nardo', Francesca Valenti², Cristina Todde', Maria Grazia Frigo' \\ I) Department of Obstetric Anaesthesia, S.G. Calibita Fatebenefratelli Isola Tiberina Hospital, Rome, Italy
}

2) Department of Anaesthesiology and Intensive Care, University of L'Aquila, Italy

Background: Many studies demonstrated excellent analgesic action of intrathecal clonidine, which acts in synergy with local anaesthetics and opioids. However, the high number of alpha2-adrenergic receptors on the myometrium makes clonidine an adjuvant potentially able to interact with the labour dynamics. The purpose of this study was to evaluate the impact of intrathecal clonidine addition in combined spinal-epidural analgesia on labour progression, local anaesthetic consumption and maternalfoetal well-being.

Results and Discussion: The study included in S group 57 parturients and in group C 50 parturients. Data relating to duration of I,II stage and the time from admission to delivery are shown in Table 1. The foetal descent curve of the group $C$ has a more linear trend compared with the control curve (Figure 1). The average consumption of local anaesthetic from the beginning of analgesia until the expulsive phase in the $\mathrm{S}$ group (group C: $35.4 \mathrm{mg}, \mathrm{S}$ group: $8.51 \mathrm{mg}, \mathrm{p}$ 0.029) was lower in a statistically significant manner.

Tab I: Duration of the first and second stage and time from admission to delivery in the sample analyzed: differences between two groups.

\begin{tabular}{l|l|l|l}
\hline & Clonidine & Sufentanil & P \\
\hline I stadium (h) & $4,0 \mathrm{I}(\mathrm{I}, 9)$ & $5,49(\mathrm{I}, 43)$ & $* 0,00 \mathrm{I}$ \\
\hline II stadium (h) & $\mathrm{I}, 33(0,89)$ & $\mathrm{I}, 29(0,78)$ & 0,0872 \\
\hline $\begin{array}{l}\text { Time from admission to } \\
\text { childbirth (h) }\end{array}$ & $5,33(2,16)$ & $6,78(\mathrm{I}, 73)$ & $* 0,006$ \\
\hline
\end{tabular}

All data are expressed as mean (SD).

*Significant.
Materials and Methods: From October 2014 to March 2015 a case control study was conducted: I07 ASA I nulliparous parturients, between I8-45 years old, singleton were enrolled. Inclusion criteria were: $\mathrm{BMI}<30$, gestational age $\geq 37$ weeks, vertex foetus, cervical dilation $>2$ to $<5 \mathrm{~cm}$, foetal presenting part between -2 to $-I$. Parturients were assigned randomly into two groups: Group C (intrathecal $2 \mathrm{mcg}$ Sufentanil $+20 \mathrm{mcg}$ clonidine) and Group S (intrathecal $2 \mathrm{mcg}$ sufentanil). Data concerning duration of the I and II stage and the time from admission to delivery were recorded. The U-test was used to compare the cervical dilatation and the duration of the second stage, a polynomial equation to create the curves of the cervical dilatation and foetal presenting part. A polynomial equation for the time of the second order was found suitable for cervical dilatation and one for the third-order time for foetal presenting part.A $P<0.05$ was considered significant.

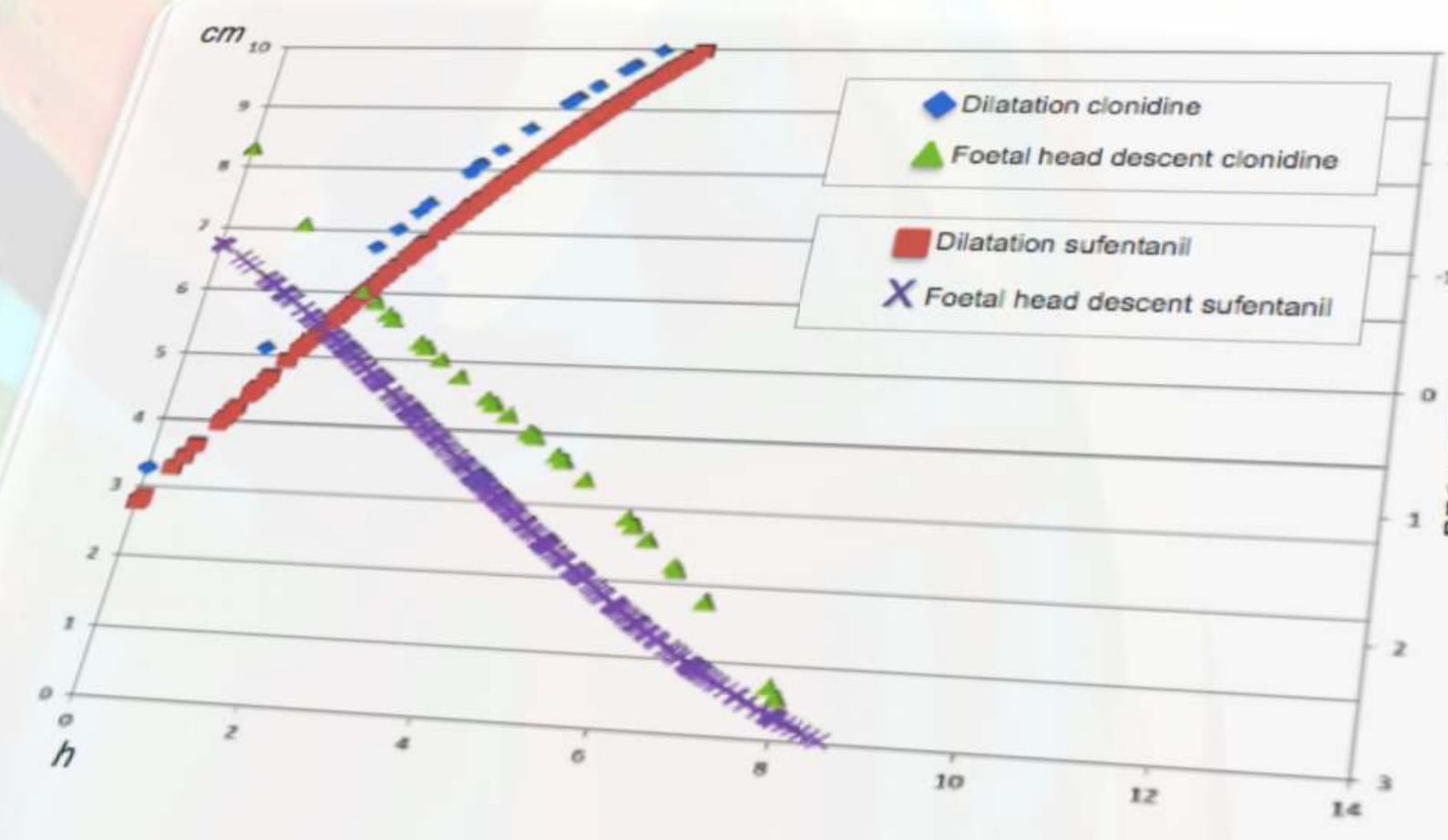

sufentanil and of the dilatation curve and descent of the foetal headt

sufentanil and with the addition of and descent of the foetal head throtion curver mcg of clonidine to sufentanil.

Conclusions: Reduction of first stage duration respect to the control group suggests a clonidine positive interaction with the myometrial dynamic. The curve obtained from the analysis of cervical dilatation and descent of foetal presenting part shows that intrathecal clonidine may be characterized by an its specific pattern of labour progression. Relating to its analgesic effect, clonidine confirms excellent analgesia in labour from the beginning, with no increase in side effects.

' Labbene II, Gharsallah H,Abderrahman A, Belhadj Amor M, Trabelsi W, Hajjej Z, Ferjani M. [Effects of I5 mcg intrathecal clonidine added to bupivacaine and sufentanil for labor analgesia].Tunis Med. 201 I Nov;89(I I):853-9.

${ }^{2}$ Chabot-Doré AJI, Schuster DJ, Stone LS, Wilcox GL. Analgesic synergy between opioid and $\alpha 2$-adrenoceptors. Br J Pharmacol. 2015 Jan; I $72(2): 388-402$. doi:

I0.I I I /bph. I 2695. Epub 20 I 4 Jul I. 